\title{
Triple Combination Inhalers in Chronic Obstructive Pulmonary Disease and Asthma
}

\author{
Maria Gabriella Matera, ${ }^{1}$ Paola Rogliani, ${ }^{2}$ Luigino Calzetta, ${ }^{3}$ and Mario Cazzola ${ }^{2}$ \\ 1. Department of Experimental Medicine, University of Campania Luigi Vanvitelli, Naples, Italy; 2. Department of Experimental Medicine, Tor Vergata University \\ of Rome, Rome, Italy; 3. Respiratory Disease and Lung Function Unit, Department of Medicine and Surgery, University of Parma, Parma, Italy
}

DOI: https://doi.org/10.17925/USPRD.2020.5.1.18

\begin{abstract}
A favorable pharmacological interaction between long-acting $\beta_{2}$ agonists, long-acting muscarinic receptor antagonists, and inhaled corticosteroids (ICSS) explains why triple therapy is effective both in chronic obstructive pulmonary disease (COPD) and asthma; however, it has been documented that the presence of an ICS may cause the occurrence of pneumonia. As there is well-documented evidence that triple therapy is effective in improving lung function and reducing the risk of exacerbation in patients with asthma and those with COPD, single-inhaler triple therapies have been developed mainly to increase adherence to treatment that often is low because of complexity introduced by the additional inhaler(s). Three single-inhaler triple therapies_-beclomethasone dipropionate/formoterol/glycopyrronium, fluticasone furoate/ vilanterol/umeclidinium, and budesonide/glycopyrronium/formoterol_are available to treat COPD, whereas no single-inhaler triple therapy has yet been approved for use in asthma, but several trials have evaluated, or are exploring, this possibility. Pivotal trials have shown that there is a role for triple therapy, mainly for single-inhaler triple therapy, in both COPD and asthma management. However, there is a real risk that the use of single-inhaler triple therapy will expand the "one-size-fits-all" approach that has conditioned the prescriptive behavior of many doctors in the recent past, with little consideration of individual patient variability when making management decisions.
\end{abstract}

\section{Keywords}

Asthma, COPD, triple therapy, single-inhaler

Disclosures: Maria Gabriella Matera has participated as a speaker and advisor in scientific meetings and courses under the sponsorship of Almirall, AstraZeneca, Boehringer Ingelheim, Chiesi Farmaceutici, GlaxoSmithKline, and Novartis; and has been a consultant to Chiesi Farmaceutici. Her department has received funding from GlaxoSmithKline and Novartis. Paola Rogliani has participated as a speaker and advisor in scientific meetings and courses under the sponsorship of Almirall, AstraZeneca, Biofutura, Boehringer Ingelheim, Chiesi Farmaceutici, GlaxoSmithKline, Menarini Group, Mundipharma, and Novartis. Her department has received funding from Almirall, Boehringer Ingelheim, Novartis, Zambon, and Chiesi Farmaceutici. Luigino Calzetta has participated as an advisor in scientific meetings under the sponsorship of Boehringer Ingelheim and Novartis; received non-financial support by AstraZeneca; received a research grant partially funded by Chiesi Farmaceutici, Boehringer Ingelheim, Novartis, and Almirall; and is, or has been, a consultant to ABC Farmaceutici, Recipharm, Zambon, Verona Pharma, and Ockham Biotech. His department has received funding from Almirall, Boehringer Ingelheim, Novartis, Zambon, and Chiesi Farmaceutici. Mario Cazzola has participated as a speaker and advisor in scientific meetings and courses under the sponsorship of Almirall, AstraZeneca, Biofutura, Boehringer Ingelheim, Chiesi Farmaceutici, Cipla, GlaxoSmithKline, Menarin Group, Lallemand, Mundipharma, Novartis, Pfizer, Verona Pharma, and Zambon; and is, or has been, a consultant to ABC Farmaceutici, Recipharm, Chiesi Farmaceutici, Lallemand, Novartis, Verona Pharma, and Zambon. His department has received funding from Almirall, Boehringer Ingelheim, Novartis, and Zambon.

Review Process: Double-blind peer review

Compliance with Ethics: This article involves a review of the literature and did not involve any studies with human or animal subjects performed by any of the authors.

Authorship: The named authors meet the International Committee of Medical Journal Editors (ICMJE) criteria for authorship of this manuscript, take responsibility for the integrity of the work as a whole, and have given final approval for the version to be published.

Access: This article is freely accessible at touchRESPIRATORY.com (C) Touch Medical Media 2020

Received: March 18, 2020

Accepted: July 27, 2020

Published Online: December 15, 2020

Citation: US Respiratory \& Pulmonary Diseases. 2020;5(1):18-23

Corresponding Author: Mario Cazzola, Department of Experimental Medicine, Tor Vergata University of Rome, Via Montpellier 1, Rome, 00133, Italy. -mail: mario.cazzola@uniroma2.

Support: No funding was received in the publication of this article.
Strategy reports from both the Global Initiative for Chronic Obstructive Lung Disease (GOLD) $2020^{1}$ and the Global Initiative for Asthma (GINA) $2019^{2}$ highlight the importance of using the triple combination of inhaled corticosteroids (ICS), long-acting $\beta_{2}$-agonists (LABAS), and long-acting muscarinic receptor antagonists (LAMAS) in the treatment of chronic obstructive pulmonary disease (COPD) and asthma, respectively. However, there is a substantial difference between the GOLD and GINA strategies. GOLD recommends adding a LAMA to an ICS/LABA combination or an ICS to a LABA/LAMA combination, depending on the different clinical situations mainly related to the presence of dyspnoea or exacerbations, with the option to refer to blood eosinophil count. ${ }^{1}$ In contrast, GINA plans to add tiotropium, the only LAMA approved for the treatment of asthma, to ICS/LABA when the disease is not well controlled and before escalating to treatment with biologics or low-dose oral corticosteroids. These recommendations are supported by pivotal clinical trials that have evaluated the effects of triple therapy in both COPD and asthma and the subsequent meta-analysis.

In this article, we critically review the literature in order to determine, if possible, the real role of triple therapy in the treatment of asthma and COPD. To address this topic, we have identified studies from EMBASE, MEDLINE, Scopus, The Cochrane Library, Web of Science, and Google Scholar. We supplemented the bibliographic database searches with backward citation tracking of relevant publications. We also searched www.clinicaltrials.gov for ongoing trials. The information thought to be more significant has been selected and commented upon.

\section{Pharmacological interaction between LABA, LAMA, and ICS}

The evidence of a favorable pharmacological interaction between LABAS, LAMAS, and ICSs is growing. For several years, there has been evidence of a pharmacological advantage in combining LABAs and ICSS in both 
asthma ${ }^{3}$ and COPD. ${ }^{4}$ In effect, bidirectional molecular interactions between corticosteroids and $\beta_{2}$-agonists are responsible for a mutual enhancement of their pharmacological effects. ${ }^{5}$ The interaction between these drugs at the level of human isolated bronchi has previously been investigated; results showed that LABAs and ICSs synergistically relax airways to an extent that is very strong at low-to-medium concentrations mainly in passively sensitized small airways, a validated ex vivo model of bronchial asthma. ${ }^{6}$ By contrast, pharmacological studies on the possible interaction between LAMAs and ICSs are very scarce. It has been documented that in human passively sensitized bronchi, LAMA/ICS combination synergistically enhanced the relaxation of medium and small airways.? This effect was attributed to higher concentrations of cyclic adenosine monophosphate (CAMP). However, no synergistic interaction was detected in non-sensitized bronchi. Nevertheless, LAMA/ICS combinations may have anti-remodeling activities in addition to the well-known bronchodilating and anti-inflammatory activity of these drugs. ${ }^{5}$

On the contrary, combining a LABA with a LAMA synergistically relaxes human non-sensitized medium and small airways, likely due to the cross talk induced by the activation of $\beta_{2}$-adrenoceptors, and the inhibition of $M_{3}$ muscarinic receptors at the level of airway smooth muscle cells. ${ }^{8}$ However, the pharmacological mechanism that explains the interaction between LABAs and LAMAs is complex and lies in the reciprocal influences of cholinergic and adrenergic systems, perhaps also at the pre-synaptic level. The exact nature of the interactions between these pathways is not fully understood, but there are interferences at many levels in airway smooth muscle cells that are also regulated by the activity of potassium channels activated by calcium and protein tyrosine kinases. ${ }^{5}$

Recently, it has been documented that the combination of LABA, LAMA, and ICS induces a synergistic bronchorelaxant effect in human passively sensitized isolated airway smooth muscle and tissue from patients with stable COPD. ${ }^{9}$ This effect seems to be related to the activation of intracellular glucocorticoid receptors and partially associated with the activation of $\mathrm{G}_{\mathrm{sc}}$ G-protein subunits of $\beta_{2}$-adrenoceptors, which cause modulation of the CAMP-dependent protein kinase A pathway. However, it is still unknown whether triple therapy synergizes the anti-inflammatory activity of the ICSs.

\section{Triple therapy in chronic obstructive pulmonary disease}

In recent years, some fundamental studies have been conducted to assess the impact of triple therapy in COPD treatment and have documented its protective effect compared with dual bronchodilation and ICS/LABA combination, relative to the risk of moderate or severe acute exacerbation of COPD. ${ }^{10-16}$ In particular, the IMPACT study (Informing the Pathway of COPD Treatment) that compared fluticasone furoate/vilanterol/umeclidinium bromide with vilanterol/umeclidinium bromide 25/62.5 $\mu \mathrm{g}$ once daily and fluticasone furoate/vilanterol 100/25 $\mu \mathrm{g}$ once daily over 52 weeks, enrolled 10,355 patients: ${ }^{14}$ and the ETHOS study (Study to Assess the Efficacy and Safety of PT010 Relative to PT003 and PT009 in Subjects With Moderate to Very Severe COPD) randomized 8,588 patients to receive two doses of budesonide/formoterol/glycopyrronium bromide (glycopyrrolate is its active moiety) 320/9.6/18 $\mu \mathrm{g}$ and 160/9.6/18 $\mu \mathrm{g}$, formoterol/glycopyrronium bromide 18/9.6 $\mu \mathrm{g}$, and budesonide/formoterol 320/9.6 $\mu \mathrm{g}$, all formulated using the new co-suspension delivery technology and administered twice-daily over a 52-week period. ${ }^{16}$ However, there have been important differences in study design and population that may have resulted in significant class or drug heterogeneity of triple therapies. Therefore, the results of such studies should be treated with caution. ${ }^{17}$ In fact, a meta-analysis found statistical and clinical heterogeneity to be a significant concern. ${ }^{17}$ Nonetheless, a British real-world observational study found that triple therapy caused a significantly greater reduction in exacerbation risk and risk of other outcomes, including acute respiratory events and prescription of an acute oral corticosteroid course, compared with LABA/LAMA combination in patients with a history of at least two exacerbations in the previous year, with an effect that was related to prior exacerbation rate and baseline blood eosinophil count..18

In effect, triple therapy seems to be clinically important when a patient is being treated with LABA/LAMA, has an eosinophilic blood count $\geq 300$ cells. $\mu \mathrm{L}^{-1}$ and still suffers from COPD exacerbations. ${ }^{19}$ A post-hoc analysis of the IMPACT study reported that the moderate and severe exacerbation rate ratio for triple therapy versus umeclidinium-vilanterol was 0.88 at a blood eosinophil count of $<90$ cells $\mu \mathrm{LL}^{-1}$ and 0.56 at counts of $\geq 310$ cells $\cdot \mu \mathrm{L}^{-1} .^{20}$

The step-up approach from dual bronchodilation to triple therapy, proposed by the GOLD strategy, ${ }^{1}$ does not reflect the important differences in COPD exacerbations (they differ in etiology, severity, and biological substrate) and therefore, is not adapted to the specific needs of the patient to be treated. ${ }^{21}$ The already mentioned post-hoc analysis of the IMPACT study documented that a treatment including an ICS in patients with COPD with higher eosinophilia is more effective in the prevention of exacerbations that required oral corticosteroids and/or are not associated with bacterial infections. ${ }^{20}$ On the contrary, adding a LAMA to an ICS/LABA combination induces significant clinical benefits in the general population with COPD and reduces the risk of moderate or severe exacerbations regardless of the blood eosinophil count, without increasing the risk of serious cardiovascular adverse events that may always be possible when a LAMA is added.22

In any case, the presence of an ICS may cause the occurrence of pneumonia, although this risk does not seem really relevant. The number needed to treat to induce one case of pneumonia as a result of the ICS/LABA/LAMA combination versus the LABA/LAMA combination was 195 patients; however, when considering the only pivotal trial that included fluticasone furoate in triple therapy, ${ }^{14}$ the number for the ICS/LABA/LAMA combination versus the LABA/LAMA combination decreased to 34 patients. ${ }^{19}$ However, this analysis did not include the results of the ETHOS study because they were not yet available. Correctly, it has been pointed out that the differences in the rate of pneumonia observed in studies with different ICSS may vary both because of the diversity in the design of the studies and their duration, or in the reporting of adverse events, as well as differences in patient characteristics that may increase the rate of pneumonia. ${ }^{23}$ Now we know that in the ETHOS study, the percentage of confirmed pneumonia in the presence of budesonide was double that observed in the formoterol/glycopyrronium bromide group, ranging from 3.5-4.5\% in the groups that included ICS use and $2.3 \%$ in the dual bronchodilation group. ${ }^{16}$

Pneumonia-related deaths are very rare in randomized studies, and the clinical relevance of ICS in pneumonia mortality is questionable considering the number of patients included in these trials. It has also been reported that mortality from pneumonia in randomized controlled trials has been 58/31,396 for users of ICS and 33/22,544 for non-users. ${ }^{24}$ Nevertheless, it is correct to check whether there are risk factors for the development of 
pneumonia, such as current smoker, age $\geq 55$ years, history of pneumonia, body mass index $<25 \mathrm{~kg} / \mathrm{m}^{2}$, and severe airflow limitation, before starting ICS therapy in a patient with COPD. ${ }^{25}$

\section{Triple therapy in asthma}

There is growing high-quality evidence showing a benefit with the addition of tiotropium bromide (versus placebo) to ICS/LABA in patients with poorly-controlled, severe asthma despite the use of ICS and LABA. ${ }^{26}$ Interestingly, add-on tiotropium bromide is effective irrespective of gender, age, body mass index, disease duration, age at asthma onset, smoking status, allergic status, forced expiratory volume in 1 second $\left(\mathrm{FEV}_{1}\right)$ reversibility, leukotriene receptor antagonist use at baseline, B16 genotype combination, race, ethnicity, and country/region. ${ }^{27}$ Moreover, the addition of tiotropium bromide is successful regardless of the type 2 status modeled using systemic markers of type 2 inflammation, namely total serum immunoglobulin E levels and blood eosinophil counts. ${ }^{28,29}$ There is also a suggestion that add-on tiotropium bromide might potentially enable a reduction in ICS dose in patients with uncontrolled asthma..$^{30}$ Further, tiotropium is a cost-effective treatment option. ${ }^{30}$

A systematic review with meta-analysis reported that adding tiotropium bromide to ICS/salmeterol combination increased pulmonary function to a clinically significant magnitude, reduced asthma exacerbations, and improved asthma control compared with ICS/salmeterol. ${ }^{31}$ Apparently, six factors predict benefit from asthma triple therapy: a high degree of reversibility (defined as $>400 \mathrm{~mL}$ following salbutamol $400 \mu \mathrm{g}$ ), a body mass index $<25 \mathrm{~kg} / \mathrm{m}^{2}$, only one exacerbation in the previous 12 months, never-smoker, age $<65$ years, and male gender. ${ }^{32}$ However, the results of a recent and comprehensive systematic review meta-analysis suggest that triple therapy does not reduce the risk of exacerbation requiring systemic corticosteroids versus ICS/LABA when the ICS dose remains the same, but can lower the risk of asthma worsening. ${ }^{33}$ Furthermore, they show that triple therapy induces statistically significant, but clinically unimportant, improvements in trough $\mathrm{FEV}_{1}$ and peak and trough forced vital capacity, but it does not affect asthma control, rescue medication use, or asthma quality of life.

Surprising, and in a way alarming, is the documentation resulting from a study that provided insights into the real-world use of tiotropium bromide in asthma in the USA, which showed that patients initiating triple therapy were among the most severe, but had high post-treatment ICS discontinuation rates. ${ }^{34}$ Analysis of medical and pharmacy claims, and electronic health record data from the Optum Research Database, has shown that currently, only $1 \%$ of patients with asthma are utilizing triple therapy. ${ }^{35}$ Patients using triple therapy had low adherence and persistence to multiple-inhaler triple therapy. Adherence to each individual triple therapy component was demonstrably higher, suggesting that patients are not using all three therapy components simultaneously. However, in a retrospective, observational cohort study of adults with persistent asthma from Japan, adherence after initiation of triple therapy was moderate to high compared with previously reported real-world evidence studies. ${ }^{36}$

The efficacy of tiotropium bromide is a class effect rather than a peculiar aspect of the drug. In fact, umeclidinium bromide and glycopyrronium bromide also appear effective in asthma, ${ }^{37,38}$ and, although they are not yet approved for use in this pathology, they are currently included in the clinical development of triple therapies that also include a LABA and an ICS.

\section{Single-inhaler triple therapy}

Although it has been suggested that it would be preferable for ICS to be added separately to patients with COPD already on single-inhaler LABA/LAMA combination in order to assess its effectiveness and to adjust its dose, ${ }^{39}$ a recent longitudinal, retrospective, cohort study reported that patients with COPD had low adherence to, and persistence with, multiple-inhaler triple therapy in a real-world setting. ${ }^{40}$ Furthermore, in a recent study, the use of a single-inhaler not only reduced the number of inhaler technique errors, but also required less time to instruct the patient than using two inhalers. ${ }^{41}$ Also, adherence to asthma treatment decreases with complexity of therapy. There is evidence that a single combination inhaler is preferred to concurrent therapy for patients with asthma with low adherence to controller therapies, likely because of the increased complexity introduced by the additional inhaler(s). ${ }^{42}$

In effect, both in COPD and asthma, the use of separate inhaler devices requiring different techniques can lead to confusion and increases the risk of incorrect use of each device with a negative impact on outcomes. ${ }^{43,44}$ On the other hand, for both COPD and asthma, single-inhalers are at least comparable in efficacy to multiple devices and without any additional safety concerns. ${ }^{45}$

\section{Single-inhaler triple therapy in chronic obstructive pulmonary disease}

In COPD, the administration of triple therapy using a single-inhaler simplifies the therapeutic regimen, which can reduce inhaler errors and consequently improve the overall benefits of treatment. ${ }^{41}$ In fact, the use of single-inhaler triple therapy can also help those who have difficulty taking more drugs or those who struggle to learn the correct inhalation technique. ${ }^{44}$ However, only one pivotal study compared triple therapy in a single-inhaler to triple therapy delivered in separate inhalers and using different LAMAs. ${ }^{10}$ The two triple therapies were equally effective and both superior to the LAMAs alone. The single-inhaler triple therapies available to treat COPD are beclomethasone dipropionate/formoterol/glycopyrronium bromide, fluticasone furoate/vilanterol/umeclidinium bromide, and budesonide/formoterol/glycopyrronium bromide.

A systematic review focused on randomized controlled trials of single-inhaler triple therapy in patients with COPD has reported a substantial reduction of the annual rate of moderate or severe exacerbations versus LABA/LAMA (15-52\%), ICS/LABA (15-35\%) and LAMA (20\%). ${ }^{17}$ The single-inhaler triple therapy was associated not only with a significantly lower risk of moderate or severe exacerbations compared with LABA/LAMA (rate ratio in the range of $0.48-0.85$ ), but also with ICS/LABA (rate ratio in the range of $0.65-0.85$ ), and LAMA (rate ratio 0.80). Additionally, it induced a larger improvement in lung function (change from baseline in pre-dose FEV 1 compared with LAMA $61 \mathrm{~mL}$; with ICS/LABA $81 \mathrm{~mL}$ after 26 weeks and $63 \mathrm{~mL}$ after 52 weeks; and LABA/LAMA $22 \mathrm{~mL}$ ). Also, quality of life, assessed using the St. George's Respiratory Questionnaire response (defined as decrease from baseline in total score $\geq 4$ units), with the single-inhaler triple therapy was superior to LAMA (odds ratio 1.32 after 26 weeks, and 1.33 after 52 weeks), and ICS/LABA (odds ratio 1.52 after 26 weeks, and 1.33 after 52 weeks), but not LABA/LAMA (odds ratio 1.22 after 52 weeks). However, the single-inhaler triple therapy was associated with a higher risk of pneumonia compared with LABA/LAMA (risk ratio 1.38).

Although these data support the use of single-inhaler triple therapy in patients with COPD, it has been pointed out that the fundamental TRIBUTE 
(Extrafine Inhaled Triple Therapy versus Dual Bronchodilator Therapy in Chronic Obstructive Pulmonary Disease) ${ }^{12}$ and IMPACT trials, ${ }^{14}$ in which triple therapy has been compared with LAMA/LABA, have methodological limitations that inherently favor triple therapy. ${ }^{46}$ Furthermore, it has been stressed that there are some circumstances in which the triple therapy should not be considered. ${ }^{47}$ In particular, patients with COPD suffering from severe multi-morbidities, such as severe arrhythmias; severe heart failure and/or ischemic heart disease; stroke, transient ischamic attacks; increased risk of infections, particularly pneumonia, bronchiectasis, tuberculosis and even non-tuberculous mycobacterial infections; and patients with $<100$ eosinophils. $\mu \mathrm{L}^{-1}$ should not be treated with triple therapy.

Although data from pivotal trials indicate that ICSS, LABAS, LAMAS, and their combinations are safe, there is still pharmacological evidence that cardiovascular toxicity of LABAS and LAMAS overlaps. ${ }^{48}$ However, each available LABA/LAMA combination has a specific cardiovascular safety profile that needs to be considered, ${ }^{49}$ while robust evidence indicates that in patients with moderate COPD and heightened cardiovascular risk, treatment with ICS/LABA does not affect mortality or cardiovascular outcomes. ${ }^{50}$ Conversely, the use of ICSs may be associated with an increase in the bronchial bacterial load in patients with COPD, and chronic bronchial infection..$^{51}$ Furthermore, in patients with obstructive lung diseases, ICS use was found to be associated with an increased risk of tuberculosis. ${ }^{52}$ There is also evidence that ICSs do not work when counts of blood eosinophils are low ${ }^{53}$ and, in any case, eosinopenia increases the risk of pneumonia. ${ }^{54}$ However, there is documentation that single-inhaler triple therapy reduced the risk of all-cause mortality versus dual bronchodilation in patients with symptomatic COPD and a history of exacerbations..$^{55}$

\section{Single-inhaler triple therapy in asthma}

In asthma, combination therapy, delivered via a single rather than separate inhalers, is recommended to increase adherence since it can be somewhat cumbersome to use separate inhalers. ${ }^{56,57}$ Patients with good compliance have better control of their asthma. Furthermore, it can also reduce the possibility of LABA overuse and ICS underuse that have the potential to cause serious adverse effects. ${ }^{56}$ The prospect is that a single-inhaler triple therapy will certainly be well accepted by patients who are currently taking tiotropium as an add-on to the usual ICS/LABA therapy.57

No single-inhaler triple therapy has yet been approved for use in asthma, but several trials have evaluated or are exploring this possibility. The two phase III trials (TRIMARAN [Triple in Asthma With Uncontrolled Patients on Medium Strength of ICS + LABA] and TRIGGER [Triple in Asthma High Strength Versus ICS/LABA HS and Tiotropium]) showed that single-inhaler triple therapy with beclomethasone dipropionate (100 $\mu \mathrm{g}$ in TRIMARAN and $200 \mu \mathrm{g}$ in TRIGGER), formoterol, and glycopyrronium bromide, two inhalations twice daily for 52 weeks in adults with uncontrolled asthma, improved lung function and was associated with a reduction of severe exacerbations compared with beclomethasone dipropionate/formoterol. ${ }^{58}$

The pivotal CAPTAIN trial (Clinical Study of Asthma Patients Receiving Triple Therapy Through A Single Inhaler), a randomized, multicenter study that evaluated once-daily single inhaler triple therapy with fluticasone furoate/vilanterol/umeclidinium bromide (100/25/31.25, 100/25/62.5, 200/25/31.25 and 200/25/62.5 $\mu \mathrm{g}$ ) versus fluticasone furoate/vilanterol (100/25 and 200/25 $\mu \mathrm{g}$ ) in 2,436 adult patients with uncontrolled asthma met the study's primary endpoint..$^{59}$ In fact, there was a significant improvement from baseline in trough $\mathrm{FEV}_{1}$ at 24 weeks of treatment $(110 \mathrm{~mL}$ when the dose of fluticasone furoate in both the triple and ICS/LABA combination was $100 \mu \mathrm{g}$, and $92 \mathrm{~mL}$ when it was $200 \mu \mathrm{g}$ ), and a 13\% reduction in the annualized rate of moderate/severe exacerbations, although this last finding was not statistically significant.

A phase II multi-center study compared mometasone furoate/indacaterol/ glycopyrronium bromide or QVM149 (80/150/50 $\mu \mathrm{g}$ and 160/150/50 $\mu \mathrm{g})$ once-daily with fluticasone propionate/salmeterol $(500 / 50 \mu g)$ twice-daily in 116 adults with asthma. ${ }^{60}$ Overall, 107 patients completed the 3-week study. QVM149 induced a larger improvement in lung function $\left(\triangle \mathrm{FEV}_{1}:+172 \mathrm{~mL}\right.$ with high-dose mometasone and $+159 \mathrm{~mL}$ with medium-dose mometasone versus fluticasone propionate/salmeterol). A higher percentage of patients did not need rescue medicine with the triple therapy (high-dose mometasone, 58\%; medium-dose mometasone, 52\%) compared with fluticasone propionate/salmeterol (45\%) during the last week of each treatment period.

The large IRIDIUM trial evaluated the efficacy and safety of two different doses of QVM149 (80/150/50 $\mu \mathrm{g}$ and 160/150/50 $\mu \mathrm{g})$ once-daily compared with mometasone furoate/indacaterol (160/150 $\mu \mathrm{g}$ and 320/150 $\mu \mathrm{g}$, respectively) as well as fluticasone propionate/salmeterol (500/50 $\mu \mathrm{g})$ twice-daily in patients with uncontrolled asthma on medium and high doses of ICS/LABA as determined by pulmonary function testing and effects on asthma control. ${ }^{61}$ QVM149 was superior to mometasone furoate/indacaterol in improving trough $\mathrm{FEV}_{1}$, but not Asthma Control Questionnaire (ACQ-7) score after 26 weeks. Furthermore, it induced a substantial reduction in moderate-to-severe and severe asthma exacerbation rates compared with fluticasone propionate/salmeterol.

The phase IIIB ARGON study, which compared once-daily QVM149 with high- (160 $\mu \mathrm{g})$ or medium-dose $(80 \mu \mathrm{g})$ mometasone to a free combination of twice-daily high-dose fluticasone propionate/salmeterol (500/50 $\mu \mathrm{g})$ plus once-daily tiotropium bromide for 24 weeks in 1,426 patients with uncontrolled asthma, met its primary endpoint.62 QVM149, administered using a Breezhaler device (Novartis, Basel, Switzerland), was comparable to fluticasone propionate/salmeterol plus tiotropium bromide in improving quality of life assessed using the Asthma Quality of Life Questionnaire in people with uncontrolled asthma. Secondary analyses showed QVM149 with high-dose mometasone improved lung function ( $\triangle$ trough $F E V$ : $96 \mathrm{~mL}$ ), asthma control, health status, and reduced moderate exacerbations compared with fluticasone propionate/salmeterol plus tiotropium bromide. Improvements in these endpoints were comparable for QVM149 medium-dose and fluticasone propionate/salmeterol plus tiotropium.

QVM149, whose approval has been recommended by the Committee for Medicinal Products for Human Use of the European Medicines Agency, is administered using a Breezhaler device with an optional digital sensor, which can be attached to the base of the inhaler. ${ }^{63}$ This sensor can record details of each administered dose and send this information via Bluetooth to an app on a smart phone or other digital device, which can in turn help the patient improve their asthma self-management.

\section{Conclusion}

Solid evidence indicates that there is a role for triple therapy, mainly for single-inhaler triple therapy, in COPD management.. 1721,31 Unquestionably, the use of such combinations can increase the patient's adherence to 
the prescribed therapy, with obvious implications on patient outcomes. Moreover, single-inhaler triple therapy seems to be deemed a cost-saving and similarly efficacious therapy relative to commonly used multiple-inhaler triple therapies, ${ }^{64}$ and versus both LABA/LAMA and ICS/LABA combination over a lifetime horizon. ${ }^{6}$ However, there is a real risk that the use of single-inhaler triple therapy will expand the "one-size-fits-all" approach that has conditioned the prescriptive behavior of many doctors in the recent past, with little consideration of individual patient variability when making management decisions. ${ }^{66}$

We believe that it is important to provide patients with COPD with precise and personalized medicine considering the complexity and heterogeneity of COPD. ${ }^{67}$ For this reason, we must always determine whether and when the addition of an ICS to the LAMA/LABA combination really induces further clinical benefit, regardless of a preventive effect on COPD exacerbations, and establish the value of this benefit. ${ }^{67}$ In any case, it is difficult to determine whether a patient with COPD who continues to suffer from exacerbations following the addition of an ICS would have been exacerbated with the same intensity and severity without this addition. ${ }^{68}$ On the other hand, the addition of a LAMA to an ICS/LABA combination elicits a significant clinical benefit, ${ }^{21}$ although it has been pointed out that treating patients with COPD with ICS/LABA plus LAMA and LABA/LAMA plus ICS should be equally effective. ${ }^{39}$ However, a real-life prescription analysis in the UK showed starting patients on ICS plus LABA results in the inevitable drift to overuse of triple therapy. ${ }^{69}$

In our opinion, it is crucial that physicians establish when to start directly with the triple therapy rather than increasing the current therapy. ${ }^{70}$ We think that all patients hospitalized because an exacerbation of COPD should be discharged with the prescription of long-term triple therapy. ${ }^{71}$ Furthermore, we completely agree with Vanfleteren and colleagues that all patients who present for the first time, and present severe airway obstruction ( $\mathrm{FEV}_{1}<50 \%$ ), are symptomatic, had frequent moderate $(\geq 2)$ or severe exacerbations $(\geq 1$ hospitalization) in the previous year, and have peripheral eosinophilia (>300 cells· $\left.\mu \mathrm{L}^{-1}\right)$, must soon receive regular treatment with triple therapy. ${ }^{47}$

Since most adults with asthma have some features considered characteristic of $\mathrm{COPD}_{1}^{72}$ there is the risk that patients with airway disease (including asthma, and asthma-COPD overlap) will be prescribed "triple therapy" as the default position. The indiscriminate use of the single-inhaler triple therapy may fall into the classic "one-size-fits-all" approach that may be practical, simple and "a safe bet" in terms of efficacy, ${ }_{1}^{73}$ but does not address the needs of all patients, ${ }^{26,73}$ and the best interest of government funding agencies. ${ }^{73}$ This contrasts with the most recent opinion on the treatment of asthma that considers it important to focus on treatable traits that can be targeted using a personalized medicine approach mainly in severe asthma. ${ }^{74}$

In effect, the GINA strategy recommends triple therapy in severe asthma before escalating to treatment with biologics or low-dose oral corticosteroids. ${ }^{2}$ However, the GINA strategy also emphasizes that the severity of asthma can change over time. As the goal of therapy is to offer the patient the minimum level of therapy capable of maintaining asthma control, also the intensity of treatment must change with the change of the severity of asthma. This means that de-escalation of triple therapy is often a need, but it could be problematic especially in patients who, well controlled, will be reluctant to stop a treatment that they perceive effective. ${ }^{26}$

Nonetheless, we believe that there is a need to assess whether it would be clinically useful to begin triple therapy earlier than currently recommended by the GINA strategy. This opinion stems from the evidence that, as already mentioned, co-administration of a LAMA and a LABA synergistically relaxes human isolated airways at the level of the medium and small bronchi. ${ }^{8}$ The synergistic interaction on small airways may explain the beneficial impact on lung hyperinflation resulting from small airway inflammation, which is highly prevalent in moderate-to-severe asthma, is associated with important patient-related outcomes in daily life, and is a key target for asthma treatment. ${ }^{75}$ Additionally, the combination of these drugs inhibits the epithelial (non-neuronal) release of acetylcholine, ${ }^{76}$ which is the main driver of the inflammatory response, ${ }^{\cdot 77}$ modulates airway smooth muscle tone in small airways; ${ }^{5}$ and causes a further increase in the density of the cholinergic nerves, thus creating a vicious circle that results in more release of acetylcholine. ${ }^{78}$

Needless to say, patients with asthma must receive regular ICS treatment simultaneously with dual bronchodilation. However, the use of ICSS, LABAS, and LAMAs in separate inhalers by patients who may present varying symptoms and inflammation should be always discouraged. ${ }^{78}$
1. Global Initiative for Chronic Obstructive Lung Disease (GOLD). Global strategy for the diagnosis, management and prevention of chronic obstructive pulmonary disease: 2020 report. Available at: https://goldcopd.org/gold-reports/ (accessed August 10, 2020).

2. Global Initiative for Asthma (GINA). Global strategy for asthma management and prevention (updated 2020). Available at: https://ginasthma.org/gina-reports/ (accessed August 10, 2020).

3. Barnes PJ. Scientific rationale for inhaled combination therapy with long-acting $\beta 2$-agonists and corticosteroids. Eur Respir J. 2002;19:182-91.

4. Cazzola M, Dahl R. Inhaled combination therapy with long-acting $\beta 2$-agonists and corticosteroids in stable COPD. Chest. 2004;126:220-37.

5. Matera MG, Page CP, Calzetta L, et al. Pharmacology and therapeutics of bronchodilators revisited. Pharmacol Rev. 2020;72:218-52

6. Calzetta L, Matera MG, Facciolo F, et al. Beclomethasone dipropionate and formoterol fumarate synergistically interact in hyperresponsive medium bronchi and small airways. Respir Res 2018;19:65.

7. Cazzola M, Calzetta L, Rogliani P, et al. Interaction between corticosteroids and muscarinic antagonists in human airways. Pulm Pharmacol Ther. 2016;36:1-9.

8. Calzetta L, Matera MG, Cazzola M. Pharmacological mechanisms leading to synergy in fixed-dose dual bronchodilator therapy. Curr Opin Pharmacol. 2018;40:95-103.

9. Rogliani P, Matera MG, Facciolo F, et al. Beclomethasone dipropionate, formoterol fumarate and glycopyrronium bromide: synergy of triple combination therapy on human airway smooth muscle ex vivo. Br J Pharmacol. 2020;177:1150-63.

10. Vestbo J, Papi A, Corradi M, et al. Single inhaler extrafine triple therapy versus long-acting muscarinic antagonist therapy for chronic obstructive pulmonary disease (TRINITY): a double-blind, parallel group, randomised controlled trial. Lancet. 2017:389:1919-29.

11. Singh $D$, Papi $A$, Corradi $M$, et al. Single inhaler triple therapy versus inhaled corticosteroid plus long-acting $\beta 2$-agonist therapy for chronic obstructive pulmonary disease (TRILOGY): a double-blind, parallel group, randomised controlled trial. Lancet. 2016;388:963-73.

12. Papi A, Vestbo J, Fabbri L, et al. Extrafine inhaled triple therapy versus dual bronchodilator therapy in chronic obstructive pulmonary disease (TRIBUTE): a double-blind, parallel group, randomised controlled trial. Lancet. 2018:391:1076-84.

13. Lipson DA, Barnacle $H$, Birk R, et al. FULFIL trial: once-daily triple therapy in patients with chronic obstructive pulmonary disease. Am J Respir Crit Care Med. 2017;196:438-46.

14. Lipson DA, Barnhart F, Brealey N, et al. Once-daily single-inhaler triple versus dual therapy in patients with COPD. N Eng/ J Med. 2018;378:1671-80.

15. Ferguson GT, Rabe KF, Martinez FJ, et al. Triple therapy with budesonide/glycopyrrolate/formoterol fumarate with co-suspension delivery technology versus dual therapies in chronic obstructive pulmonary disease (KRONOS): a double-blind parallel-group, multicentre, phase 3 randomised controlled trial. Lancet Respir Med. 2018;6:747-58.
16. Rabe KF, Martinez FJ, Ferguson GT, et al. Triple inhaled therapy at two glucocorticoid doses in moderate-to-very-severe COPD. N Eng/ J Med. 2020;383:35-48.

17. Langham S, Lewis J, Pooley N, et al. Single-inhaler triple therapy in patients with chronic obstructive pulmonary disease: a systematic review. Respir Res. 2019;20:242.

18. Voorham J, Corradi M, Papi A, et al. Comparative effectiveness of triple therapy versus dual bronchodilation in COPD. ERJ Open Res. 2019;5:00106-2019.

19. Cazzola M, Rogliani P, Calzetta L, et al. Triple therapy versus single and dual long-acting bronchodilator therapy in COPD: a systematic review and meta-analysis. Eur Respir J. 2018;52:1801586.

20. Pascoe S, Barnes N, Brusselle G, et al. Blood eosinophils and treatment response with triple and dual combination therapy in chronic obstructive pulmonary disease: analysis of the IMPACT chronic obstructive pulmonary disease:
trial. Lancet Respir Med. 2019;7:745-56.

21. Cazzola M, Calzetta L, Rogliani P, et al. Triple therapy versus dual bronchodilation and inhaled corticosteroids/long-acting $\beta$-agonists in COPD: accumulating evidence from network meta-analyses. Pulm Ther. 2019;5:117-26.

22. Calzetta L, Cazzola M, Matera MG, Rogliani P. Adding a LAMA to ICS/LABA therapy: a meta-analysis of triple combination therapy in COPD. Chest. 2019;155:758-70

23. Agusti A, Fabbri LM, Singh D, et al. Inhaled corticosteroids in COPD: friend or foe? Eur Respir J. 2018;52:1801219.

24. Almagro P, Martinez-Camblor P, Soriano JB. Inhaled corticosteroids and pneumonia mortality in COPD patients. Eur Respir $\mathrm{s}$ 
2019;54:1901035

25. Crim C, Dransfield MT, Bourbeau J, et al. Pneumonia risk with inhaled fluticasone furoate and vilanterol compared with vilanterol alone in patients with COPD. Ann Am Thorac SOC. 2015;12:27-34

26. Cazzola M, Puxeddu E, Matera MG, Rogliani P. A potential role of triple therapy for asthma patients. Expert Rev Respir Med. 2019:13:1079-85.

27. Kerstjens HA, Moroni-Zentgraf $\mathrm{P}$, Tashkin DP, et al. Tiotropium improves lung function, exacerbation rate, and asthma control, independent of baseline characteristics including age, degree of airway obstruction, and allergic status. Respir Med. 2016;117:198-206

28. Casale TB, Bateman ED, Vandewalker $\mathrm{M}$, et al. Tiotropium Respimat add-on is efficacious in symptomatic asthma, independent of $\mathrm{T} 2$ phenotype. J Allergy Clin Immunol Pract. 2018;6:923-35.e9.

29. Szefler SJ, Vogelberg C, Bernstein JA, et al. Tiotropium is efficacious in 6- to 17-year-olds with asthma, independent of T2 phenotype. J Allergy Clin Immunol Pract. 2019;7:2286-95.e4.

30. Mansfield L, Bernstein JA. Tiotropium in asthma: from bench to bedside. Respir Med. 2019:154:47-55.

31. Rodrigo GJ, Castro-Rodriguez JA. What is the role of tiotropium in asthma? A systematic review with meta-analysis. Chest 2015;147:388-96

32. Singh D, Virchow JC, Canonica WG, et al. Characteristics of prominent response to triple therapy in patients with asthma uncontrolled on ICS/LABA: a stratified analysis of the TRIMARAN and TRIGGER studies. Eur Respir J. 2019;54(Suppl. 63):RCT3779.

33. Sobieraj DM, Baker WL, Nguyen E, et al. Association of inhaled corticosteroids and long-acting muscarinic antagonists with asthma control in patients with uncontrolled, persistent asthma: a systematic review and meta-analysis. JAMA. 2018;319:1473-84.

34. Averell CM, Laliberté F, Duh MS, et al. Characterizing real-world use of tiotropium in asthma in the USA. J Asthma Allergy. 2019;12:309-21.

35. Bogart M, Chastek B, White J, et al. Treatment patterns and disease burden of triple therapy in asthma. Am J Respir Crit Care Med. 2020:201:A7742.

36. Suzuki T, Fairburn-Beech J, Sato K, Kaise T. Clinical characteristics, treatment patterns, disease burden, and persistence/adherence in patients with asthma initiating inhaled triple therapy: real-world evidence from Japan. Curr Med Res Opin. 2020;36:1049-57.

37. Kerwin E, Wachtel A, Sher L, et al. Efficacy, safety, and dose response of glycopyrronium administered by metered dose inhaler using co-suspension delivery technology in subjects with intermittent or mild-to-moderate persistent asthma: randomized con

38. Lee $L A$, Yang $S$, Kerwin $E$, et al. The effect of fluticasone furoate/umeclidinium in adult patients with asthma: a randomized, dose ranging study. Respir Med. 2015;109:54-62

39. Lopez-Campos JL, Marquez-Martín E, Ortega-Ruiz F. Triple therapy vs. triple therapy in COPD. Arch Bronconeumol. 2017;53:419-20.

40. Bogart M, Stanford RH, Laliberté F, et al. Medication adherence and persistence in chronic obstructive pulmonary disease patients receiving triple therapy in a USA commercially insured population. Int I Chron Obstruct Pulmon Dis. 2019:14:343-52

41. van der Palen J, Moeskops-van Beurden W, Dawson CM, et al. A randomized, open-label, single-visit, crossover study simulating triple-drug delivery with Ellipta compared with dual inhaler combinations in patients with COPD. Int I Chron Obstruct Pulmon Dis. 2018:13:2515-23.

42. Marceau C, Lemiere C, Berbiche D, et al. Persistence, adherence, and effectiveness of combination therapy among adult patients with asthma. J Allergy Clin Immunol. 2006;118:574-81.

43. Bosnic-Anticevich S, Chrystyn H, Costello RW, et al. The use of multiple respiratory inhalers requiring different inhalation techniques has an adverse effect on COPD outcomes. Int I Chron Obstruct Pulmon Dis. 2016;12:59-71.

44. Dekhuijzen PN, Lavorini F, Usmani OS. Patients' perspectives and preferences in the choice of inhalers: the case for Respimat ${ }^{\boxplus}$ or HandiHaler ${ }^{\varpi}$. Patient Prefer Adherence. 2016;10:1561-72.

45. Zhang S, King D, Rosen VM, Ismaila AS. Impact of single combination inhaler versus multiple inhalers to deliver the same medications for patients with asthma or COPD: a systematic literature review. Int I Chron Obstruct Pulmon Dis. 2020;15:417-38.

46. Suissa S, Ariel A. Triple therapy in COPD: only for the right patient. Eur Respir J. 2019;53:1900394.

47. Vanfleteren LEGW, UIIman A, Nordenson A, et al. Triple therapy (ICS/LABA/LAMA) in COPD: thinking out of the box. ERJ Open Res. 2019;5:00185-2018.

48. Ora J, Cavalli F, Cazzola M. Management of patients with asthma or COPD and cardiovascular disease: risks versus benefits. In: Martínez-García MÁ, Pépin J-L, Cazzola M (eds). Cardiovascular Complications of Respiratory Disorders. Sheffield, UK: European Respiratory Society. 2020:66-81.

49. Rogliani P, Matera MG, Ritondo BL, et al. Efficacy and cardiovascular safety profile of dual bronchodilation therapy in chronic obstructive pulmonary disease: a bidimensional comparative analysis across fixed-dose combinations. Pulm Pharmacol Ther. 2019;59:101841

50. Vestbo J, Anderson JA, Brook RD, et al. Fluticasone furoate and vilanterol and survival in chronic obstructive pulmonary disease with heightened cardiovascular risk (SUMMIT): a double-blind randomised controlled trial. Lancet. 2016;387:1817-26.

51. Garcha DS, Thurston SJ, Patel AR, et al. Changes in prevalence and load of airway bacteria using quantitative PCR in stable and exacerbated COPD. Thorax. 2012;67:1075-80.

52. Castellana G, Castellana M, Castellana C, et al. Inhaled corticosteroids and risk of tuberculosis in patients with obstructive lung diseases: a systematic review and meta-analysis of non-randomized studies. Int I Chron Obstruct Pulmon Dis. 2019:14:2219-27.

53. Bafadhel M, Pavord ID, Russell REK. Eosinophils in COPD: just another biomarker? Lancet Respir Med. 2017;5:747-59.

54. Ernst P. Blood eosinophils in COPD and the future risk of pneumonia. Eur Respir J. 2018:52:1800981.

55. Lipson DA, Crim C, Criner GJ, et al. Reduction in all-cause mortality with fluticasone furoate/umeclidinium/vilanterol in COPD patients. Am J Respir Crit Care Med. 2020:201:1508-16.

56. Papadopoulos NG, Arakawa H, Carlsen KH, et al. International consensus on (ICON) pediatric asthma. Allergy. 2012;67:976-97.

57. Cazzola M, Rogliani P, Matera MG. Ultra-LABAs for the treatment of asthma. Respir Med. 2019;156:47-52.

58. Virchow IC, Kuna P, Paggiaro P, et al. Single inhaler extrafine triple therapy in uncontrolled asthma (TRIMARAN and TRIGGER): two double-blind, parallel-group, randomised, controlled phase 3 trials. Lancet. 2019:394:1737-49.

59. GlaxoSmithKline. Phase III CAPTAIN study of Trelegy Ellipta in patients with asthma meets primary endpoint. May 2, 2019 Available at: www.gsk.com/en-gb/media/press-releases/phaseiii-captain-study-of-trelegy-ellipta-in-patients-with-asthma-meetsprimary-endpoint/ (accessed August 10, 2020).

60. Watz H, Hohlfeld JM, Singh D, et al. Letter to the editor: indacaterol/glycopyrronium/mometasone furoate compared with salmeterol/fluticasone propionate in patients with asthma: a randomized controlled cross-over study. Respir Res. 2020;21:87

61. Novartis. Novartis announces positive results from phase III IRIDIUM study of inhaled combination QVM149 in patients with uncontrolled asthma. September 30, 2019. Available at: www.novartis.com/news/media-releases/novartis-announcespositive-results-from-phase-iii-iridium-study-inhaled-combinationqvm149-patients-uncontrolled-asthma (accessed August 10, 2020).

62. Gessner C, Kornmann O, Maspero J, et al. Fixed-dose combination of indacaterol/glycopyrronium/mometasone furoate once-daily versus salmeterol/fluticasone twice-daily plus tiotropium once-daily in patients with uncontrolled asthma: a randomised, phase IIIb, non-inferiority study (ARGON). Resp Med. 2020;170:106021.

63. Prescriber.co.uk. CHMP recommends new asthma triple combination inhaler. May 13, 2020. Available at: www.prescriber. co.uk/news/chmp-recommends-new-asthma-triple-combinationinhaler/ (accessed August 10, 2020).

64. Goodall E, Schroeder M, Lozano-Ortega G, et al. PRS39 Cost-effectiveness of a new single inhaler triple therapy (SITT) versus multiple inhaler triple therapies (MITT) to treat chronic obstructive pulmonary disease (COPD) in Canada. Value Health. 2018:21(Suppl. 3): $\$ 410$

65. Ismaila AS, Risebrough N, Schroeder M, et al. Cost-effectiveness of once-daily single-inhaler triple therapy in COPD: the IMPACT trial. Int J Chron Obstruct Pulmon Dis. 2019;14:2681-95.

66. Singh D. Pharmacological treatment for COPD; GOLD 2017 changes direction. Br J Clin Pharmacol. 2017;83:935-7.

67. Cazzola M, Rogliani P, Stolz D, Matera MG. Pharmacologica treatment and current controversies in COPD. F1000Res. 2019:8:F1000 Faculty Rev-1533

68. Cazzola M, Rogliani P, Puxeddu E, et al. An overview of the curren management of chronic obstructive pulmonary disease: can we go beyond the GOLD recommendations? Expert Rev Respir Med. 2018;12:43-54

69. Brusselle G, Price D, Gruffydd-Jones K, et al. The inevitable drift to triple therapy in COPD: an analysis of prescribing pathways in the UK. Int J Chron Obstruct Pulmon Dis. 2015:10:2207-17.

70. Cazzola M, Calzetta L, Rogliani P, Matera MG. The challenges of precision medicine in COPD. Mol Diagn Ther. 2017;21:345-55.

71. Cazzola M, Rogliani P, Matera MG. Escalation and de-escalation of therapy in COPD: myths, realities and perspectives. Drugs. 2015;75:1575-85.

72. Rogliani P, Ora J, Puxeddu E, Cazzola M. Airflow obstruction: is it asthma or is it COPD? Int I Chron Obstruct Pulmon Dis. 2016:11:3007-13.

73. Beasley R, Hardy J, Hancox R. Asthma prescribing: where are we headed? Respirology. 2017:22:1487-8.

74. MCDonald VM, Clark VL, Cordova-Rivera L, et al. Targeting treatable traits in severe asthma: a randomised controlled trial. Eur Respir J. 2020;55:1901509.

75. van der Meer AN, de Jong K, Hoekstra-Kuik A, et al. Dynamic hyperinflation impairs daily life activity in asthma. Eur Respir J. 2019;53:1801500

76. Cazzola M, Calzetta L, Puxeddu E, et al. Pharmacological characterisation of the interaction between glycopyrronium bromide and indacaterol fumarate in human isolated bronchi, small airways and bronchial epithelial cells. Respir Res. 2016;17:70.

77. Kistemaker LE, Gosens R. Acetylcholine beyond bronchoconstriction: roles in inflammation and remodeling. Trends Pharmacol Sci. 2015;36:164-71.

78. Cazzola M, Rogliani P, Matera MG. The latest on the role of LAMAS in asthma. J Allergy Clin Immunol. 2020;146:1288-91. 